MARTÍNEZ, L., SILVA, C., MORANDÉ, M. y CANALES, L. (2010). Los jóvenes ciudadanos: reflexiones para Decala, No32, pag $105-118$. Década, №32, pág. $105-118$

MORÁN, M. Y BENEDICTO, J. (2000). Jóvenes y ciudadanos. Madrid: INJUVE.

RIZO, M. (2006). Conceptos para pensar lo urbano: el abordaje de la ciudad desde la identidad, el habitus y

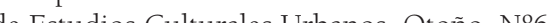

SAINTOUT, F. (2009). Jóvenes: el futuro llegó hace rato. Percepciones de un tiempo de cambios: familia, escuea, trabajo y politica. Buenos Aires: Prometeo.

\title{
Políticas de reconstrucción posterremoto en Chile: dispositivo biopolítico, objetivación/subjetivación y resistencia'. Aproximaciones desde una lógica foucaultiana
}

Reconstruction policies post-earthquake in Chile: bio-political device, objectivation / subjectivation and resistance.

Approximations from foucaultianan logic

Christian Arriagada D.

Licenciado en Trabajo Social. Magister @ en Trabajo Social. Correo electrónico: cnarriag@uc.

Resumen

El siguiente articulo presenta algunas aproximaciones a la política de reconstrucción desarrollada en Chile luego del terremoto/tsunami que afectó al pais el 27 de febrero del año 2010. Se propone la idea de dispositivo biopolítico desde una arista del pensamiento de Foucault como posibilidad interpretativa frente a las acciones politicas desarrolladas tras la catástrofe. Se intenta vislumbrar algunas de las lineas del dispositivo puesto en marcha, considerando los procesos de objetivación y subjetivación puestos en marcha por la politica, y, a su vez, las resistencias presentadas frente a dichos procesos.

Palabras clave. Reconstrucción, desastres, dispositivo, biopolitica.

\section{Abstract}

The following article presents some approximations to the politics of reconstruction developed in Chile after the earthquake / tsunami that struck the country on February 27, 2010. This paper proposes the idea of bio-political device, from an edge of Foucault's thought, as interpretative possibility to the political actions developed after the catastrophe. It is intend to show some lines of the device put in pace considering the processes of objectivation and subiectivation implemented by the policy and the resistance presented against these processes.

Key words. Reconstruction, disasters, device, bio-politics,

\section{Introducción}

El terremoto y tsunami sufrido en el país el 27 de tebrero de 2010, trajo numerosas consecuencias de destrucción en varias regiones y en diversas localidades tanto urbanas como rurales, especialmente en las regiones VII y VIII, que resultaron ser las más afectadas, sobre todo su lado costero (CEPAL, 2010, pág. 38)
El Gobierno de Chile puso en marcha un plan de reconstrucción para poder enfrentar la emergencia con la intención de paliar los diversos efectos que tuvo el megasismo en las zonas de mayor desastre (MINVU, 2011). Estas estrategias de reconstrucción del gobierno fueron acompañadas por otra serie de intervenciones del ámbito privado y de la sociedad civil ${ }^{2}$. De esta manera, 
nos encontramos con escenarios en los cuales se desenvuelven una serie de esfuerzos que buscan o tienen como objetivo el poder desarrollar estrategias que permitan superar los efectos que tuvo la catastrofe en las diferentes zonas del país. Este plan se anuncia por parte del gobierno en el discurso dado por el Presidente Sebastián Piñer en 2010, como un plan que levantará el alma del país y que traerá una mayor libertad, justicia y fraternidad $^{3}$

Esta serie de iniciativas puestas en marcha pueden tener diversas consecuencias y efectos para la población (positivos o negativos), de allí que este trabajo busque elaborar algunas aproximaciones desde una perspectiva postestructuralista foucauliana, respecto de cómo se podría desarrollar un análisis con esta lógica al (los) dispositivo(s) de intervención puestos en marcha tras la catástrofe. Lo anterior se propone en cuanto una catástroLe es una dimensión ontológica que potencia desarrollo de nuevas práctica politicas, donde el se aprovecha para la generación de órdenes políicos deternina plos y estos producen nuevos significa $y$ relacios de poder, una huevos significados y relaciones de poder, una vez que se ponen en marcha (Soldani, 2011, pág. 54) De aquí que este ensayo busque abrir algunas alternativas para el análisis de la política de reconstrucción, considerando como elemento particular la idea Foucault, específicamente retomando tres movimientos dentro de este, a saber: la objetivación la subjetivación y la resistencia, como engranajes desde los cuales se tensionarán algunos aspectos del acontecimiento político que ha implicado la reconstrucción

\section{La idea de dispositivo en Michel Foucaul}

Considerando la obra desarrollada por Foucault,

se ha propuesto que este más que entregar una Si miramos, por ejemplo, la página web levantemosciudadania.cl, nos encontraremos con que por lo menos existen 50 organizaciones
del tercer sector que estän o estuvieron involucradas en mayor o menor medida en intervenciones relacionadas con los efectos del terremoto-tsunami sufrido en el pais. Si bien no todas intervienen en una misma localidad, si en varias de ellas existen a lo menos dos o tres instituciones que están interviniendo. Ver: www.levantemosciudadania cl

De acuerdo al discurso desarrollado en Caleta Lo Rojas, el 16 de abril de 2010, el Presidente de la República, anuncia el Plan de
reconstrucción. en donde señala "Hoy dia quiero compartir no solamente con ustedes, sino que con todos los chilenos, el plan de reconstrucción, en donde señala: "Hoy día quiero compartir, no solamente con ustedes, sino que con todos los chilenos, el plan de significa no solamente levantar las escuelas destruidas, los hospitales inutilizados, los puentes que se caveron. las viviendas que se destruveron sino que algo mucho mas profundo levantar el alma de nuestro pais" Y a continuación agrega: "Y esa nobleza y ese destruyeron, sino que algo mucho mas profundo, levantar el alma de nuestro pais'. Y a continuacion agrega: "Y esa nobleza y ese poner en marcha nuevamente nuestro pais y levantar todo lo que el terremoto y maremoto destruyeron y poder construir una patria y un país más libre, más grande, más justo y más fraterno." (a negrita y cursiva no aparecen en el texto original).

De acuerdo a Colina (1984) en Foucault no se encontraría un método formal e interpretativo, sino que más bien un método dedicado a desmetodizar, el que se puede entender como una huida desesperada ante ese riesgo de los términos, ante todo exceso de saber que se presenta como una forma de intemperancia. incluiría lo lingüístico y lo no-lingüístico en un mismo movimiento, siendo en sí mismo la red que se establece entre esos elementos. En segundo lugar, el dispositivo tendría una función estratégica concreta, pues se inscribe en un juego de poder determinado. Y tercero, el disposit sería algo general, una red en la que se incluye la episteme, aquello que permite en una determinada sociedad disting permite en una determinada sociedad distinguir entre lo aceptado como enunciado científico, de lo que no es científico. Considerando esta primera aproximación, al concebir Foucault el dispositivo como una serie de elementos en red, no propone un específico (a modo de esencia) que dichos dispositivos podrían tener, de aquí que se propongan como conjuntos multilineales, como un ovillo o madeja cuyas líneas siguen diversas direcciones y forman siempre procesos en desequilibrio; son líneas quebradas que sufren variaciones en su dirección, de tal forma que los objetos visibles, los enunciados formulados, las fuerzas en ejercicio, y los sujetos en posición serían unas especies de vectores o posiciones (Deleuze, 1990, pág. 155), y que estarían en constante movimiento.

Siguiendo a Deleuze (1990), él destaca que se distinguirían dos dimensiones en un dispositivo, a saber, curvas de enunciación y curvas de visibilidad, en este caso el dispositivo sería una máquina hecha para hacer ver y para hacer hablar, es decir por una parte tienen sus propios regímenes de luz que iluminan figuras variables y que no se pueden separar del propio dispositivo, y por otra parte, regímenes de enunciación conformados por líneas de enunciación "en las que se distribuyen las posiciones diferenciales de sus elementos; y si las curvas son ellas mismas enunciaciones, y si las curvas son ellas mismas enunciaciones, lo son porque distribuyen variables..." (Deleuze, 1990, pág. 155). De esta manera no son ni sujetos, ni objetos, sino regímenes suceptibles de ser definidos desde estas dos dimensiones -siempre por otros regímenes- con sus bifurcaciones, mutaciones, transformaciones, hibridaciones, etc.

De esta manera, un dispositivo viene encauzado por diversas líneas, que no son siempre congruentes entre sí y por ello no matienen posiciones estáticas. Es todo un conjunto de discursos/prácticas que son marcas, cuadrículas de organizacion social que hacen posibles ciertas acciones e impiden otras, y, a la vez, configuran realidad, pues fijan normas y verdades, lo que se puede decir o no, e incluso lo que se puede pensar en un contexto determinado (Healy, 2001, pág. 57), y se confrontan en un territorio en el cual se validan unos y se marginan otros, y desde este proceso emergen los objetos sociales del lenguaje.

Desde esta interpretación, los discursos, como generadores de verdad, se producen por medio de algunos procedimientos que hacen posible que ciertos enunciados se desarrollen en determinados momentos, lugares y ubicaciones institucionales, haciendo que algunas cosas se puedan decir y otras se marginen (Healy, 2001 pág. 58). Se trata de saberes que están implicados directamente con el poder (Healy, 2001, pág. 58), de tal forma que no existe un saber objetivo y que siempre toda categoría con pretensión de verdad tenga un carácter de poder disciplinario (que busca dar ordenamiento, posicionarse como abarcador, objetivador de realidad). Esta idea de poder es otro de los elementos constitutivos de un dispositivo, es la línea de fuerzas que rectifican de cierta forma las curvas de visibilidad y enunciación, trazan trayectorias, tangentes, operan idas y vueltas del ver al decir, como flechas que penetran palabras y cosas, y que están en per manente batalla internándose en cada lugar de dispositivo (Deleuze, 1990, pág. 155).

Con este análisis, Foucault busca mostrar "cómo las relaciones de poder pueden penetrar materialmente en el espesor mismo de los cuerpos sin tener incluso que ser sustituido por la representación de los sujetos" (Foucault, 1992, pág. 156) De esta manera, interesa para este análisis que el poder entrecruza cada una de las relaciones, entre cada punto del cuerpo social (entre una familia, el maestro y su alumno, el hombre y la mujer, etc.), atraviesan estas relaciones de poder que en ningún caso se refieren a la proyección simple y pura del gran poder soberano sobre los ndividuos, sino que más bien refiere a ese suelo movedizo y concreto sobre el que este pode obtiene las condiciones de su funcionamiento (Foucault, 1992, pág. 157).

\section{Política, objetivación y subjetivación del}

individuo moderno

La idea de dispositivo emerge, en parte, para dar explicación a los movimientos de las relaciones de poder, y específicamente, para nombrar aquello que se realiza en una actividad de gobierno, en el arte práctico, en esa manera de hacer que orma parte de la capacidad inventiva y de la fuerza circulante de las técnicas, de ese orden 
instrumental en el que se inscribe la idea de gobierno (Soldani, 2011, pág. 55), y que se plasma en el cuerpo de los individuos.

Se trata de desarrollar, desde esta óptica, una analítica de las problemáticas de gobierno resituando los estudios en torno al Estado, donde ya no se considere su intervención como un intervención abstracta, sino que, más bien, a la propia idea de gobierno como una construcción historica que ha derivado en una matriz en la que se conjugan políticas y proyectos políticos, los planes y las prácticas de determinadas autoridades-económicas les, médicas, etc- quienes buscan encauzar y administrar l vida de los otros, iluminando una vía por medio de concepciones como lo bueno, lo normal, lo saludable, lo virtuoso, lo eficiente, lo rentable, etc (Rose \& Miller, 1992).

Esta idea de gobierno comparte con aquella concepción de gubernamentalidad elaborada por Foucault. Para él, este problema de la gubernamentalidad comienza con el descubrimiento de la idea de población como ente susceptible de control, refiere a ese conjunto de instituciones, procedimientos, análisis y reflexiones, y a las tácticas que permiten ejercer poder sobre la población. En este sentido, se rescata que goberna un Estado se asume como el poner en práctica la sea, teniendo una forma de vigilancia, de control sobre los habitantes de un territorio (Aguilera 2010, pág. 27), sobre el cuerpo que sufre la inscripción disciplinaria en la sociedad moderna, en nombre de una racionalidad forzada (Aguilera 2010, pág. 29), por tanto, se trata de la "conducción de la conducta', una forma de actividad práctica, que tiene el proposito de conforn 作 guiar o alectar la conducta, tanto de uno mism. como de los otros" (Haidar, 2005, pág. 246). decir de Foucault sería:

"un conjunto de instituciones, procedimientos, análisis y reflexiones que han permitido ejercer esta forma especifica del poder [el gobierno]. que tiene por blanco la población, por form principal de saber la economía política y por instrumentos técnicos esenciales los dispositivos de seguridad" (Haidar, 2005, pág. 247. Cit. Foucault, 1991, pág. 25).

Se trata de un poder que se ejerce sobre la vida, que emerge por la transformación que sufren los mecanismos de poder -que se manifiesta en el siglo XVII-, donde "el viejo derecho de hacer morir o dejar vivir fue remplazado por el poder de hacer vivir o de arrojar a la muerte" (Foucault, 2008, pág. 131); se trata de la instauración del bio-poder, ese poder que se propone como tarea la administración de la vida bajo dos formas principales, que constituirían dos polos de desamedio de relaciones: por una parte un polo centrado en el cuerpo como máquina, donde su adiestramiento, el aumento de sus aptitudes, la extorsión de sus fuerzas, el crecimiento de su utilidad y docilidad, su integración a sistemas de control eficaces y económicos, quedan asegurados por los procedimientos de poder disciplinarios, una especie de anatomopolítica del cuerpo humano; y un segundo polo (al parecer formado desde mediados del siglo XVIII) centrado en el cuerpo-especie, en un cuerpo transido por la mecánica de lo viviente y que sirve de soporte a los procesos biológicos (proliferación, nacimientos y mortalidad, nivel de salud, longevidad y duración de la vida), los que son tomados a su cargo por una serie de intervenciones y de controles reguladores, una biopolítica de la población.

Esta gestión positiva de la vida se distinguiría por ese control que se ejercería sobre el cuerpo: "El cuerpo es abordado como un objeto a ser analizado y separado en sus partes constitutivas. El objeto de la tecnología disciplinaria es forjar un cuerpo dócil, 'que pueda ser sujetado, usado, transformado y puesto a prueba"' (Dreyfus \& Rabinow, 2001, pág. 183). De esta forma se comienza a objetivar al individuo moderno, en cuanto se generan toda una serie de disciplinas que pretenden ejercer control sobre él, y no se trata de la mera dominación -aunque se asume la posibilidad de ella-, sino que más bien del análisis, el poner a la vista el cuerpo, utilizando diversos medios, la estadística, la ciencia, la milicia, la intervención política, etc.

Junto a este movimiento de objetivación del sujeto moderno se desarrolla otro que tiene que ver con la subjetivación del individuo moderno, que Foucault la enmarca con lo que denomina tecnología confesional, donde se impulsa por medio de sistemas de control externo el autoexamen de conciencia, y será el deseo cultural de conocer la verdad sobre sí mismo el que impulsa la interrogación por la verdad, de aquí que se trate de comprender las operaciones que tienen estas tecnologías del yo, los tipos particulares de discursos y las técnicas particulares que supuestamente revelan nuestra identidad (Dreyfus \& Rabinow, 2001, pág. 205). Se trata de "un proce- so de individuación que tiene que ver con grupos o personas y que se sustrae a las relaciones de fuerzas establecidas como saberes constituidos: es una especie de plusvalía" (Deleuze, 1990, pág. 156), y es un proceso que solo se da en la medida en que el dispositivo lo haga posible. ble. Se trata principalmente de líneas facultativas de dominación de uno mismo (ser dueño de sí mismo), que constituyen la subjetivación, las producciones de subjetividades siempre móviles que se trasladan de un dispositivo a otro (Deleuze, 1990, pág. 156). Este proceso de subjetivación, al igual que el de objetivación, es parte importante movimiento denominado gubernamentalidad, en c en él conviven dos lógicas, por una parte, una ascendente que propone que quien quiera gobernar el Estado debe primero saber gobernarse a sí mismo, en otro nivel a su familia, en otro sus bienes o dominio, y llegará a dominar el Estado; y, por otra parte un lógica descendente, es decir cuando un Estado está bien gobernado, los padres de familia saben gobernar bien, sus familias, sus bienes, sus dominios y riqueza, y en última instancia los individuos son capaces de conducirse como se debe (Foucault, 2007a, pág. 195). Es con estas dos técnicas que se entrecruzan (disciplina y tecnologías del yo) que el individuo moderno pasa a constituirse como un objeto de conocimiento, tanto para sí mismo como para los demás, y un objeto que dice la verdad acerca de sí mismo (teniendo como propósito el conocerse a sí mismo y ser conocido), un objeto que aprende a efectuar cambios sobre sí mismo (Dreyfus \& Rabinow, 2001, pág. 206). Este doble movimiento es el que completa parcialmente un dispositivo, lo forja junto con las otras tres líneas de movimiento (curvas de luz, de enunciación y línea de fuerzas).

De esta manera se puede vislumbrar el análisis de la gubernamentalidad como aquel que alude a la articulación entre el gobierno de las conductas, las tecnologías de gobierno y una racionalidad particular (Haidar, 2005, pág. 246). En este sentido, el gobierno puede involucrar acciones y relaciones de diferentes tipos, algunas concernientes a la relación con uno mismo, otras a las relaciones interpersonales, de instituciones sociales y comunidades, que contribuyen a "estructurar el posible campo de acción de los otros" (Foucault, 1992, pág. 181), campo que no necesariamente es de confrontación y lucha, sino de hibridación de relaciones de poder Desde esta perspectiva, interesa estudiar la racionalidad del gobierno como una forma de pensar en la naturaleza de su ejercicio (quién puede gobernar/qué es gobernar/qué o quién es gobernado), que es capaz de transformar cierta forma de esta actividad en algo concebible y factible, tanto para aquellos que la practican como para los individuos sobre los cuales se ejerce (Haidar, 2005, pág. 247).

En este movimiento que vislumbra Foucault serán clave, precisamente las relaciones de poder que se analizan como capilares y productivas, es decir, por un lado lo social se configura en el campo de fuerzas inestables pero efectivas en cuanto a su alcance micro, que se ejercen desde una multiplicidad de puntos (de ahí capilaridad), y por otro lado productivas en cuanto sujetan produciendo a los individuos mediante regulaciones normativas y normalizadoras, como también en relación a los juegos de verdad que rigen en una época determinada las prácticas de sí y los sujetos morales. En este sentido, dicha productividad se vislumbra como una sujeción (assujettisement) que constituye a los sujetos a partir de la multiplicidad de los cuerpos, las fuerzas, energías, materias, pensamientos, etc. (Amigot, 2005, pág 130)

Para desarrollar este análisis, Foucault propone una analítica del poder que estaría siempre imbricada con otras nociones que se vinculan a ell como lo son el saber, la verdad y el sujeto, que él considera como sus preocupaciones persistentes las aborda en términos de las prácticas, donde las relaciones de poder cobrarían protagonismo:

"Así fui conducido a plantear el problema del saber/poder que para mí es, no el problema fundamental, sino un instrumento que permite analizar de la manera que me parece más exacta el problema de las relaciones entre sujeto y juegos de verdad" (Foucault, 1984, pág. 718. En: Amgot, 2005, pág. 143)

Desde esta perspectiva, los juegos de verdad serían performativos, pero estarían siempre enrelazados con las condiciones específicas desd las cuales emergen, cuestión que lleva a considerarlos con base en las relaciones de poder, a la idea de un discurso como estrategia situado en un contexto histórico, en el interior de prácticas de reglas de producción de la verdad, "un conjunto de procedimientos que conducen a un cierto resultado, que puede ser considerado, en función de sus principios y de sus reglas de procedimientos como válido o no" (Amigot, 2005, pág. 147). En este sentido, los enunciados serían conside- 
rados como acontecimientos discursivos, que si bien instituyen su propio referente, estos aparecen en situaciones concretas y siempre vinculados otros enunciados, de tal manera que el campo de enunciados (conjunto de cosas dichas), estaria se establece y relaciona, juego de exteriorida que se daría en complejas relaciones de fuerza (Amigot, 2005, págs. 147-148).

Resistencias, libertad y poder: hacia una analítica del poder

En Foucault encontramos una nueva forma -"nueva", entendida como la creatividad variable de acuerdo a los dispositivos (Deleuze, 1990, pág. 157)- de investigar la economía de las relaciones de poder, la cual:

"consiste en tomar como punto de partida las formas de resistencia contra los diferentes tipos de poder. (...) consiste en utilizar la resistencia como un catalizador químico que permita poner en evidencia las relaciones de poder, ver dónde se inscriben, descubrir sus puntos de aplicación y los métodos que utilizan." (Foucault, 1988, pág. 5) Se trata de analizar las relaciones de poder por medio del enfrentamiento de las estrategias que se despliegan en un campo estratégico de interacciones (Castro R., 2006, pág. 54). Estas relaciones de poder suponen -para desarrollarse- de libertad, que no corresponde para Foucault al reilibertad que no corresponde para Foucant al reide una propiedad que nos garantiza su presencia inextinguible, sino que es un problema estratégico, unido a la acción del poder y de los individuos (Castro R., 2006, pág. , pág. pág. 53). Así, la liberno tiene cabida en el pensamiento foucaultiano, sino que corresponde a una labor de desarraigo respecto de la identidad que se le impone a los individuos (Castro R., 2006, pág. 54).

Ahora bien, si se entiende que una relación de poder se caracteriza por ser "una acción que oper sobre las acciones eventuales, o actuales, de los individuos" (Castro R, 2006, pág. 55), se puede entender porque no existe esta sin la libertad, pues, para que se desarrolle, supone el reconocimiento del otro como un actor y, del mismo modo, que ante dicha relación se abra un campo de confrontación, es decir, de respuestas, efectos, reacciones, etc. Así, Foucault propone: "El pode se ejerce únicamente sobre 'sujetos libres' y sólo enredado en un juego de exterioridad con el cual no de la utopia ni tampoco la sitúa en el ámbito tad como una lucha por llegar a ser lo que somos en la medida en que son "libres"' (Foucault, 1988, pág. 15), o sea, donde los sujetos son capaces de diversas conductas, reacciones y comportamientos, y se ven enfrentados con un campo de posibilidades. Se trata de una relación de incitación recíproca y de lucha entre una y otra: "En el corazón mismo de la relación de poder, "procorazon mismo de la relación de poder, y "provocandola" de manera constante, se encuentra la obstinación de la voluntad y la intransitividad de la libertad" (Foucault, 1988, pág. 16). En otras palabras, estas relaciones de poder son formas de conducción del comportamiento que tienen como condición para operar la virtualidad del comportamiento y, por lo tanto, no anulan aquello sobre lo que actúan (Castro R, 2006, pág. 55). Cabe señalar que, si es que la acción es irrenunciable a la analítica del poder, en esta analítica no habría clausura (Castro R., 2006, pág. 57), y es por esto que Foucault propone:

“(...) siempre tenemos la posibilidad de cambiar la situación (...) no podemos colocarnos al margen de la situación, y en ninguna parte estamos libres de toda relación de poder. Pero siempre podemos transformar la situación. No he querido decir, por tanto, que estamos siempre atrapados, antes bien, al contrario, que somos siempre libres" (Castro R., 2006, pág. 57. Cit. Foucault, 1999, pág. 422)

Foucault propone, por tanto, que no habría poder sin resistencias, que, al igual que el poder, estarían presentes por todas partes y no habría un lugar del gran rechazo. En este sentido se señala que la vida confiere un estatuto a las fuerzas de resistencia en un marco de poder centrado sobre la vida, do "varias resistencias", que pese a ser móviles y transitorias, siempre se establecen vinculadas a las relaciones de poder. Ellas "no pueden existir sin una multiplicidad de puntos de resistencia que desempeñen el papel de adversario, de blanco y de punto de apoyo" (Garcés, 2005, pág. 94). Estas resistencias singulares, a su vez, no pueden estar en relación de exterioridad al poder, de aquí que siempre se tenga que tener en cuenta que todos los efectos que la vida produzca al ser solicitada en contra del poder que la invade, serán puntos, focos, nudos internos de la red misma de poder (Garcés, 2005, pág. 95), que en este caso responde a la idea de gubernamentalidad en cuanto prácticas que se ciernen sobre la administración de la vida de control y gobierno político (Elícer, 2008, pág. 155), desde donde 155), desde donde poder sobre todo "encendiendo algunos puntos del cuerpo, ciertos momentos de la vida, determinados tipos de comportamiento" (Garcés, 2005 pág. 95. Cit. Foucault, 1976b [VS], pág. 117).

Por último, Foucault señala algunas características particulares que tendrían estas luchas, pues no se trata de cualquier oposición, no son una simple lucha contra la autoridad, por esto define con mayor precisión aquello que tienen en común (Foucault, 1988, págs. 6-7): a) Son luchas "transversales", o sea, no se limitan a un país, a una forma de gobierno político o a una economía particular; b) Su objetivo son los efectos del poder como tales; se cin poder incontrolado que cualquier mecanismo ejerce sobre los cuerpos; c) Son luchas inmediatas, pues, por un lado los individuos critican instancias de poder que son lo más cercana a ellos, o sea, buscan al enemigo inmediato; $y$, por otro lado, no esperan solucionar el problema en un futuro, en relación con una escala teórica de explicación o con un orden revolucionario, sino que son luchas anárquicas; d) Cuestionan el estatus del individuo, pues están en contra del "gobierno de la individuación" en dos sentidos: por un lado subrayan el derecho a ser diferentes como individuos, y por otro atacan todo aquello que puede aislar al individuo, hacer romper sus lazos con otros, y con esto atarlo a su propia identidad coercitivamente; e) Se oponen a los efectos del poder vinculados con el saber, la competencia y la calificación. Luchan contra los privilegios del saber, su circulación y funcionamiento, al igual que contra la deformación, las representaciones mistificadoras que se les imponen; f) Por último, estas luchas se mueven en torno a la pregunta ¿quiénes somos?, o sea, son un rechazo a estas abstracciones de la violencia estatal económica e ideológica que ignora quienes somos individualmente, y es también un rechazo a una inquisición científica o administrativa que determina quién es uno.

De esta manera, son luchas que tienen por objetivo atacar una técnica, una forma de poder, y no a una institución, grupo o elite de poder. En definitiva es esa forma de poder que se ejerce sobre la vida inmediata, sobre la vida cotidiana que "clasifica a los individuos en categorías, los designa por su propia individualidad, los ata a su propia identidad, les impone una ley de verdad que deben reconocer y que los otros deben reco-

La literatura señala que la noción de desastre "natural" no existiría, siendo muchas de las amenazas naturales, por lo general inevitables (piénsese en ciclones, inundaciones, sequías y terremotos), precisamente "amenazas" en el sentido de que pueden potencialmente causar
daño al hombre, a las economias y al medio ambiente si estos no se encuentran preparados para ellas (Lavell, 2000).

nocer en ellos" (Foucault, 1988:7), es decir, esa lorma de poder que los transforma en sujetos, en y atado a su propia identidad por la conciencia o conocimiento de sí mismo (tecnologías del yo).

Así, estas resistencias evidencian las relaciones de poder que se generan en un determinado dispositivo, ponen en cuestión las estrategias que se utilizan para enunciar y vislumbrar, para objetivar y subjetivar, por parte de los dispositivos de gobierno en un determinado escenario.

\section{Algunas aproximaciones de análisis para} la política de reconstrucción

El plan de reconstrucción lanzado por el gobierno en el año 2010, tendría dentro de sus componentes uno físico (que refiere a los objetivos de reconstrucción física: vivienda, calles, etc.) y otro social (que refiere a la reconstrucción psicosocial de las personas afectadas por el terremoto) (MINVU, 2010). En este sentido, es un plan que se propone como una de sus tareas el ayudar a los individuos no solo en reconstruir su espacio vital, sino que también acompañarlos con herramientas que les permitan fortalecerse social y psicológicamente (generar espacios que permitan el fortalecimiento del capital social, ayudarlos superar el trauma que significó el terremoto o tsunami, desarrollar su capacidad de resiliencia, entre otros.) (MINVU, 2010). De esta manera, en un primer acercamiento general se puede vislumbrar que se trata de una política que busca ejerce una gestión positiva de la vida de los individuos, de reconstrucción de sus "vidas", que en este caso se solicita en base a la posibilidad de daño o trauma, no solo físico (daños en infraestructura), sino que también sociales y psicológicos.

En este caso, la gestión positiva de la vida, desde la experiencia internacional, es literal, en cuanto las intervenciones de reducción de impacto de desastres buscan precisamente el reducir las pérdidas de vidas que estos provocarían, dado el valor intrínseco que tendría la vida de los afectados (Naciones Unidas, 2010; Naciones Unidas, 2009; y García \& García, 2005). Lo interesante es que, en base a ese valor intrínseco, se juegan tros valores que impulsarian las acciones a realizar para evitar los desastres ${ }^{5}$, como por ejemplo, a idea de generar intervenciones de prevención sus dos sentidos, sujetos a un control (disciplina) 
debido a la interrupción de un supuesto curso normal que la sociedad tendría, el que se vería afectado por este evento externo (Naciones Unidas, 2009)

En dicha intervención, el concepto de vulnerabilidad se presenta como predominante al momento de evaluar y actuar frente a un desastre. Dicho concepto referiría -en parte- a una determinada configuración social, que es resultado de variados factores (entre ellos: económicos, políticos y sociales) que se conjugan (García \& García 2005) y que hacen que en un determinado momento una comunidad, familia o persona sur un desastre que las acciones humanas no han sido suficientes para refrenar el impacto de la amenaza natural (Cilento, 2005)

Si bien es mucho más lo desarrollado por la literatura respecto de la relación entre desastre y vulnerabilidad, el concepto de vulnerabilida vido asocia sociedad sociedad del riesgo ${ }^{6}$. Algunos autores señalan (Soldani, 2011) que la característica principa de esta descripción de la sociedad es la pérdida efectiva de un supuesto centro gravitacional y su constante búsqueda: la seguridad. El riesgo, en el caso de una catástrofe, sería una anticipación de esta, y por otro lado, ella sería una transformación del riesgo en realidad, se trataría de un metadispositivo en torno al cual se generarían una serie de dispositivos de los cuales dependería su funcionamiento (Soldani, 2011, pág. 66)

Lo interesante es que este metadispositivo seguiría como principio la posibilidad del cálculo -de prever y calcular las consecuencias de los hechos catastróficos- haciendo el futuro decible en el presente, y proponiendo la evaluación de los riesgos como una actividad ad infinitum, debido a que ellos son continuos y por ende, la eleccion che el riesgo (eje con (eje constitutivo de este tipo de sociedad) ejerce su completa potencialidad, apareciendo en esta economía de gobierno y de previsión con un carácter milagroso, pues, aparece como algo que se impone desde arriba y que impregna la realidad (Soldani, 2011, pág. 68). En este sentido, el riesgo y amenaza se presenta cada vez más como el problema, y su medición -legitimada por una economía particular en base a la seguridad- como la solución, pasando a tener como foco, más que las víctimas, la optimización de la fuerza destructiva de la catástrofe "para lograr algo como un nuevo New Deal local" (Soldani, 2011, pág. 69)

El cálculo como principio, si bien, se presenta en la literatura como un tema asociado a la seguridad, no es exclusivo a ella, sino que se traspasa a distintos saberes. En el caso de la política de reconstrucción posterremoto en Chile, representa una política que se aplica desde un conjunto heterogéneo de actores, donde se involucran no solo los entes de la institución gubernamental, sino que toda otra serie de actores que buscan poder intervenir a una población. En este sentido, no solo buscan reconstruir las viviendas para que se conduzca la vida nuevamente de manera normal, sino que también se busca reconducirla sicológicamente ${ }^{7}$, comercialmente ${ }^{8}$, culturalmen$\mathrm{te}^{9}$, sustentablemente $^{10}$, participativamente ${ }^{11}$ Dos de las principales exposiciones de esta descripción de sociedad las encontramos en Ulrich Beck (ver por ejemplo: "La sociedad
del riesgo: hacia una nueva modernidad" " "La sociedad mundial del riesgo") y en Niklas Luhman (ver por ejemplo: "Sociologia del riesgo").

En una noticia del 16 de abril se señala: "Actividades recreativas, creación de espacios libres y terapias psicológicas gratuitas forman parte de las medidas tomadas por instituciones públicas y privadas para normalizar la vida de las personas tras el terremoto." http:// Www.uandesweekly.cl??p=1104. Consullado el 15 de octubre del 2011

Según el diario online diariopyme, SERCOTEC habría lanzado un subsidio que beneficiará a cinco mil microempresarios de las zonas afectadas por el terremoto (noticia del 19 de mayo). Ver: http://www.diariopyme.com/2010/05/sercotec-abre-postulacion-a-subsidiopost-terremotol

De acuerdo a una noticia del 19 de octubre del 2010, el Consejo Nacional de la Cultura y las artes entregó más de 258 millones a la región de O'Higgins para reconstruir o restaurar edificios patrimoniales de la región. Ver: http://www.vi.cl/sociall/reconstruccion-post-
terremoto

10 En una noticia del 5 de abril del 2010 se señala que se desarrollará en la comuna de Yumbel una feria de "Emprendimiento para la competencias y experiencias de utilidad en los procesos de construcción de soluciones de habitabilidad y de sustento familiar" Ver:

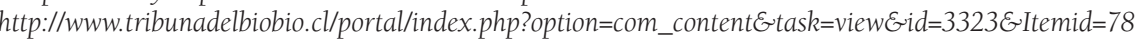

1 De acuerdo a una noticia del 31 de julio del 2010, en Talca se desarrolló un Cabildo participativo de reconstrucción, donde la ciudadania fue fundamental para desarrollar los planes de trabajo. Ver: http://www.levantemosciudadania.cl/archives/2524/commentpage-1\#comment-273. Así también, en la región del Maule (según una noticia del 9 de julio) organizaron el Seminario (Re) construir el pais: Territorio, Ciudadanía y Género, después del que una serie de mujeres de la region dieran a conocer su propuesta de trabajo para a reconstrucción. Ver: http://www.levantemosciudadania.cl/archives/2399/comment-page-1\#comment-269

etc. En este sentido, se puede interpretar como un espacio en el cual una serie de saberes, es decir discursos/prácticas, se ponen en juego, disputándose entre sí, frente a una población caracterizada por haber recibido algún daño después del terremoto-tsunami, tratándose de diversos poderes que buscan encauzar aquello que consideran más relevante más acorde a sus propias experticias, más legítimo de atender ${ }^{12}$ En este caso se trat mas legitimo de atender donde se eleva todo un aparato de intervención hacia las distintas localidades, que considera diversas estrategias, se involucran diverso ac y diversos elementos que se ponen en juego en la política.

Así, esta política estaría atravesada por ciertos regímenes de visibilidad y de enunciación; de luz en cuanto se define, se caracteriza a ciertos individuos, y con ello se les hace ver de acuerdo al saber específico con el que se los invoca y en ese preciso momento de visibilidad se les enuncia, se les da un nombre (microempresario, carente de vivienda, ciudadano, mujer, afectados sicológicamente, etc.) y con ello se les busca sujetar al haberse cruzado con un otro poder, por haber tenido algo que ver con un dispositivo de poder que emerge dada la catástrofe

En ella también se genera el doble movimiento de objetivación/subjetivación con el que se busca hacer objetivo el conocimiento sobre las personas afectadas por el terremoto. De acuerdo a la información entregada por MIDEPLAN, existiría una medición desarrollada por medio de la encuesta Panel CASEN, que entregaría la información detallada respecto de la situación socioeconómica de las familias afectadas por el terremoto, la que permitiría tener una línea de base para poder desarrollar políticas que permitan "mejorar las condiciones de vida de las familias afectadas"13.

Desde la interpretación, se trataría de objetivar a aquellos afectados por el terremoto, se les carac-

12 Respecto de esta idea de legitimidad, es interesante el planteamiento de Didier Fassin, quien postula la biolegitimidad como un nuevo poder, donde no es tanto el poder sobre la vida lo que se juega, sino el poder de la vida en sí, ese reconocimiento de aquello que significa.

3 Al respecto ver: http://www.mideplan.cl/index.php?option=com_contentEview=article $E$ idd=5687:finaliza-encuesta-panel-casen-post-

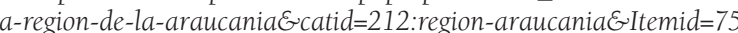

14 "Yo lo he dicho muchas veces: el alma de un país y el temple de un pueblo no se miden en tiempos de calma y tranquilidad, se miden en tiempos de tormenta y en tiempos de adversidad. Y quiero decir con mucho orgullo que hemos visto que el alma de Chile es un alm
noble y que el temple de nuestro pueblo es un temple de coraje." Discurso presidencial del 16 de abril de 2010 .

Desde el momento en que sucede la tragedia, toda una serie de acciones se comienzan a organizar en torno a ella. Hospitales, fundaciones, organizaciones civiles, universidades, el Estado, empresas privadas, e incluso un sinfin de actividades individuales de grupos de familiares, vecinos, etc. que no pertenecian a ningün tipo de organización, se organizan para ir en "ayuda de" las zonas màs afectadas. dignas de una intervención política por sus coto diciones particulares, pero no de cualquier tipo sino de una política que permita gestionar posidiciorar signas de vida A su vez, se les permite hablar desde el sí mismo, se les entrevista par con sicologicos, se hacen recuen-

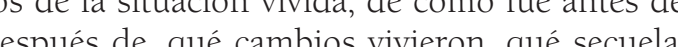
ienen, en definitiva, se someten a ciertas tecnologías del yo que los hacen hablar de sí mismos. Y, e tuvo sevaro pais lreapacidad de gobierno que rando como característica de dicho gobierno el temple que como pueblo tuvo Chile al momento 14 como una virtud digna de reconocerse, como una actitud digna de un buen gobierno de sí de la propia conducta y propia del alma de los lógica ascendente- de un buen gobierno que se desarrollaria por parte del Estado dado este equiuyen su alumbramiento, el saber político, el saber social, el saber de la experiencia estética lántropo, todos ellos en un campo, sicologico, de enfrentamiento ${ }^{15}$, cada uno con un campo de posibilidades infinitas de acción, tratando de seducir, persuadir, disuadir al otro.

Considerando este escenario y, en particular, el desplegado tras la tragedia, se presentaron una serie de manifestaciones que se desarrollaron en 
el país, específicamente en la zona mayormente afectada por el terremoto y tsunami, en contra de los planes del dispositivo de reconstrucción que el gobierno ha desarrollado. Entre los días 12 y 14 de abril del 2010, se presentaron al menos 3 manifestaciones en contra de estos planes de reconstrucción que el gobierno estaba impulsando para las zonas que se vieron más afectadas en lérminos de estructuras por el terremoto y tsun mi. En la región del Bío-Bío específicamente. En una de ellas -desarrollada en Talcahuano- se manifestó por parte del alcalde de la zona que expresamente querían ser sujetos de la reconstrucción y no objeto de ella ${ }^{16}$. Por otra parte, 20 de una manifestación en Dichato, comuna de Tomé, cuyo motivo era la imposibilidad de poder construir nuevamente sus viviendas a la orilla de mar por razones de seguridad, de acuerdo a lo planteado por el gobierno ${ }^{17}$. Tras ella se desarrolló una votación por parte de la población en la plaza del lugar para recolectar firmas y tener su propia propuesta de reconstucción ${ }^{18}$. En estos casos el tema central que demandan los habitantes de las poblaciones afectadas es la inclusión de sus propuestas en los planes de reconstrucció que se han generado por parte del Estado.

Se trataría, desde la interpretación, de una serie de resistencias al(los) dispositivo(s) puesto(s) en marcha por el gobierno, que no solo viene rectamente de el, sino que también por todas las que se hino que tambien por todas las iniciativas que se han desarrollado en nombre de un gobierno. Se trata de entender estas manifestaciones no contra un soberano o un grupo de poder, sino que ha de intentarse -sin negar a posibilidad de esta acción- buscar contra quedispositivos de sa que eso, ¿como se desarrollan estas luchas?, ¿que formas toman ellas?, ¿cómo se reacciona frent a ellas?, ¿cuáles son los efectos del poder contra los que se enfrentan los individuos?, ¿contra que se reacciona?, ¿qué regímenes de visibilidad y enunciación alimentan estas luchas?... Se trata de poder insertarse en los intersticios, en esos espacios de fractura, de quiebre, de fisuras del poder, para desde allí poder explicar cómo funcionan las relaciones de poder en este espacio particular, en este microescen lar, en ese micrescenario construido. Hay que 保 ras", para desde allí "desenmarañar las líneas de un dispositivo, [que] es en cada caso levantar un mapa, cartografiar, recorrer tierras desconocidas, y eso es lo que Foucault llama el 'trabajo en terreno'” (Deleuze, 1990, pág. 155).

\section{Algunas consideraciones finales}

El análisis hasta aquí presentado muestra algunas aproximaciones desde la idea de dispositivo biopolítico en Foucault que se encuentran aún en desarrollo. No obstante, se pueden vislumbrar algunas consideraciones que en ningún caso estarán acabadas como verdad estática, sino que son una posibilidad de interpretación.

Si consideramos que la política de reconstrucción posterremoto se visualiza como un dispositivo biopolítico, se vislumbra cómo ella no necesariamente representa una política que permitirá levantar el alma del país y que traerá mayor libertad, justicia y fraternidad, sino que más bien se desarrolla como un campo en el que se hibridan diferentes relaciones de poder que se enfrentan desde diversos saberes en una lucha específica.

Lo anterior se propone si consideramos que el dispositivo puesto en marcha se considera un conjunto multilineal, donde diversas líneas lo cruzan, líneas para "hacerlos ver" frente a otro y "hacerlos hablar". Así, por una parte se objetiva a los usuarios afectados por el terremoto, convocándolos desde diversos saberes para lograr gestionar positivamente sus vidas, y a la vez se les subjetiva en cuanto se les permite hablar del sí mismo, interrogándoles acerca de su verdad particular, de su forma de vivir (sicológica, social, económicamente) después del terremoto, y

16 De acuerdo a las declaraciones del alcalde Gastón Saavedra, para el diario La Nación del día 14 de abril del 2010 , las razones de 1 a manifestación eran: "Queremos una ley de reconstrucción, queremos un plan de Talcahuano y queremos ser sujetos de la reconstrucción y no objetos de la reconstrucción."

En: http://www.lanacion.cl/noticias/site/artic/20100414/pags/20100414145525.html. Visitado el 23/8/201

17 Al respecto, se puede consultar el Programa de Reconstrucción Nacional de Viviendas, donde se explicita que en el caso de que la vivienda haya sido arrasada por el tsunami, no se puede volver a construir en el mismo espacio en que estaba antes. Ver: http://www. gobiernodechile.chinformat20ro//3/programa-chle-unido-reconstruye-mejo.him. Vistado el 24/8/2011

18 Lo anterior, de acuerdo a lo señalado por el portal de la radio Cooperativa, donde los pobladores se refirieron a la problemática que estaban viviendo como "tsunami social", Ver: http:///www.cooperativa.cl/habitantes-de-dichato-acusaron-tsunami-social-por-plan-de-
reconstruccion/prontus_nots/2010-08-23/090925.html. Revisado el 23/8/2011 con ello se rescata su coraje y temple como una actitud virtuosa y por ello digna de reconocerse pues, a la vez nos habla de un gobierno desarrollado desde el sí mismo y que se expande hacia el Estado.

Pero estos procesos de subjetivación/objetivación tienen sus consecuencias, sobre todo cuando existen relaciones de poder que son las relaciones de fuerza que forjan la dirección de los regímenes de luz y enunciación. Son aquellos regímenes de saber-poder particular que se forjan en este espacio/tiempo determinado, y que se ponen en juego, disputándose entre si, tre sí, para hacer ver una verdad particular respecto de aquello a encauzar, saberes que se presentan en un campo de enfrentamiento. Se constituye todo un aparato de intervención, un conjunto de estrategias que se disputan en un espacio particular, la definición "verdadera" de los usuarios afectados por el terremoto. Con ello no solo se disputa entre los saberes de conducción de gobierno e instituci nes, sino que también entran en juego los saberes particulares de cada usuario, son esas resistencias que se realizan por parte de la población denunciando aquellas relaciones de poder específicas que buscan forjar una identidad particular, que se niegan y rechazan el aceptar una identidad forjada por otro, y que por ende resisten con estrategias que buscan esta liberación, que buscan atacar esta técnica particular de poder que se forja sobre las vidas de cada uno.

De esta manera, más que un espacio donde se forje la libertad, se construye un espacio de gestión, de control, de visibilidad de la propia vida, un espacio donde la libertad no existe más que como una estrategia, como esa labor de desarraigo a la identidad que se impone desde un gobierno particular. Así también, más que un espacio fraterno y justo, con la política de reconstrucción se desenvuelve un espacio de enfrentamiento, lucha y resistencia constante, que no necesariamente constituye un espacio donde un poder superior se impone sobre otro, sino que más bien se refiere a ese espacio de relaciones, de hibridaciones de poderes particulares, de saberes específicos que se disponen de una manera determinada, que ocupan diversas posiciones, y que desde allí se enfrentan por criterios de veracidad. En este enfrentamiento, más que la fraternidad y la justicia, se visualiza desde la interpretación un escenario particular de resistencias a una verdad que se imponga sobre otra, un espacio en el que lejos de encontrar una unica forma de relacion los usuarios y la política (en este caso fraterna y usta), encontramos más bien un constante enfrentarse, desde los microprocesos de definición, un espacio en el que un saber busca sobrevivir, busca tornarse abarcador busca decir la verdad, busca derribar a cualquier otra verdad que se presente, sin por ello alcanzarlo.

Ahora bien, específicamente ¿cómo se desarrollan estas luchas en la cotidianidad, en la materialidad de los "cuerpos"?, ¿Cuáles son los saberes específicos desde los cuales se ejercerían as resistencias a las identidades impuestas por los cálculos y mediciones de los saberes convocantes?, ¿qué espacios en los intersticios de las relaciones de poder son compartidos por los saberes en disputa?, ¿qué efectos de las relaciones de poder específicas hacen que se reaccione con una intensidad u otra?, son algunas de las cuestiones abiertas a resolver desde esta perspectiva.

\section{Bibliografía}

AGAMBEN, G. (2008). ¿Qué es un dispositivo? Conferencia pronunciada en la Universidad de La Plata otubre 2005. En M. Beger, \& C Carrizo, Estado civil y ciudadanos sin Estado Paradojas del ejercicio de derechos en cuestiones ambientales. Córdoba: Narvaja

AGUILERA, R. (2010). Biopolítica, poder y sujeto en Michel Foucault. Universitas. Revista de Filosofía, Derecho y Política (11), págs. 27-42

AMIGOT, P. (2005). Relaciones de poder, espacio subjetivo y prácticas de libertad: análisis genealógico de un proceso de transformación de género. Tesis doctoral, Universitat Autònoma de Barcelona, Facultat de Psicología, Barcelona.

CASTRO, R. (2006). Microfísica de la libertad: Foucaul y lo político. Hermenéutica intercultural: Revista de Filosofía (15), págs. 49-78

CEPAL. (2010). Terremoto en Chile: una primera mirada al 10 de marzo del 2010. Santiago: Naciones Unidas.

CILENTO, A. (abril-junio de 2005). Capacidad de resistencia, vulnerabilidad y cultura de riesgos. Espacio Abierto. Cuaderno Venezolano de Sociología, 14(2), 265-278

COLINA, F. (1984). Foucault o el método invisible. Rev. Asoc. Esp. Neuropsiquiatría, IV (11), págs. 312-318.

DELEUZE, G. (1990). ¿Qué es un dispositivo? En G. Deleuze, Michel Foucault, filósofo, págs. 155-163. Barcelona: Gedisa.

DREYFUS, H., \& RABINOW, P. (2001). Michel Foucaul Mas allá del estructuralismo y la hermenéutica. Buenos Aires, Argentina: Nueva Vision. 
ELIÉCER, J. (2008). Participación política juvenil como políticas de acontecimiento. Revista Argentina de Sociología (11), págs. 148-168.

FOUCAULT, M. (Julio-Septiembre de 1988). El sujeto el poder. Revista Mexicana de Sociología, 50 (3), págs.
3-20.

FOUCAULT, M. (1992). Microfísica del poder (Tercera ed.). J. Varela, \& F. Alvarez-Uria, Edits. Madrid, Espana: La Piqueta

FOUCAULT, M. (2007a). La Gubernamentalidad. En G. Giorgi, \& F. Rodríguez, Ensayos sobre bipolítica: Excesos de vida (págs. 187-215). Buenos Aires, Barcelona México: Paidós.

FOUCAULT, M. (2008). Historia de la sexualidad: la voluntad de saber Buenos Aires, Argentina: Siglo XXI.

GARCÉS, M. (2005). La vida como concepto político. Athenea Digital (7), págs. 87-104

GARCíA, A., \& GARCÍA, M. (2005). Concepciones subyacentes en el manejo e investigación sobre desastres. (5) 57), págs. 123-142

HAIDAR, V. (2009). Bipolíticas post-foucaultianas: Pensar el gobierno de la vida entre la filosofia política, la sociología y la cartografía del presente. Papeles del CEIC (Revisión Crítica), 2, págs. 13-29.

HEALY, K. (2001). Trabajo social: perspectivas contémporaneas. Madrid: Morata.

MINVU. (2010). Campamentos y aldeas. Documeno institucional (PPT)

MINVU. (2011). Plan de Reconstrucción MINVU. Chile Unido Reconstruye Mejor. Dirección de Reconstrucción. Santiago: Equipo de Dirección de Reconstrucción.

NACIONES UNIDAS. (2009). Terminología sobre reducción del riesgo de desastres. Recuperado el 4 de juni de 2011, de Estrategía Internacional para la reducción de desastres. http://www.unisdr.org/eng/terminology/ UNISDR-Terminology-Spanish.pdf

NACIONES UNIDAS. (2010). Reducción del Riesgo de Desastres: Un instrumento para alcanzar los Objetivos de Desarrollo del Milenio. Kit de Cabildeo para Parlamentarios, International Strategy for Disaster Reduction.

RORTY, R. (1988). Foucault y la Epistemología. En D Couzens, Foucault (págs. 51-60). Buenos Aires: Nueva Visión.

ROSE, N., \& MILLER, P. (Junio de 1992). Political power beyond the State: problematics of government. The British Journal of Sociology, 43 (2), págs. 173-205.

SOLDANI, G. (2011). Políticas de la catastrofe. Nuevos paradigmas entre excepción, gobierno, riesgo y soberanía. Leviathan-Cadernos de Pesquisa Política (2), págs.
54-77.

\section{COMENTARIO DE LIBRO:}

"INVESTIGACIÓN CUALITATIVA" Miradas desde el Trabajo Social

Dra. Nilsa Burgos O. Espacio Editorial, Buenos Aires, 2011 *

Dr. Leonardo Oneto P Escuela de Trabajo Social. Pontificia Universidad Católica de Chile.

El libro que se comenta puede ser considerado una obra para la artesanía de la investigación cualitativa en Ciencias Sociales, esto por ser su autora una gran artesana de oficio en el tema, y porque cuando uno recorre sus 160 páginas va descubriendo en el estilo y el contenido una riqueza que tributa a su cilatada experiencia y a su voluntad de incluir el aporte de profesionales de larga trayectoria dedicados a la investigación y la formación en investigación social en América Latina y el Caribe.

El título de la obra, "Investigación Cualitativa" define el aporte de este texto a la revisión, a partir del nivel metodológico, de los múltiples enfoques vas teóricas desde las cuales se ha abordado los procesos de Investigación de este orden. El subtítulo "Miradas desde el Trabajo Social", no define una cuestión adjetiva de la obra sino su núcleo fundamental, es una reflexión sobre la investigación cualitativa desde Trabajo Social, refiriéndola como práctica tanto investigativa como de formación profesional en investigación.

En efecto, el texto presenta la investigación cualitativa como abierta al empleo de diferentes métodos, interesada en la vida cotidiana, valorando las perspectivas de las personas participantes. Considera que la persona que investiga es el principal instrumento y que la creatividad, el pensamiento reflexivo y crítico resultan fundamentales.

La autora estima que nuestra valoración como trabajadoras y trabajadores sociales tiende a ser de subordinación a otras disciplinas. Su postura no es de competencia, sino de colaboración con estas, reconociendo las importantes aportaciones al entendimiento de la diversidad entre las humanas y los humanos. Señala que el hecho de trabajar con poblaciones diversas, aunque sean en su mayoría gente pobre, nos permite entender y visibilizar a personas que probablemente son ignoradas por la academia. Por lo tanto es necesario que se real-

La Doctora Nilsa M. Burgos Ortiz es Catedrática e investigadora en la Universidad de Puerto Rico en Rio Piedras, Escuela Graduada
de Trabajo Social desde 1983 Obtuvo su doctorado en Columbia University en la ciudad de Nueva York y su maestría en la Universida de Trabajo Social desde 1983. Obtuvo su doctorado en Columbia University en la ciudad de Nueva York y su maestría en la Universidad de Puerto Rico ce la labor de profesionales de Trabajo Social con la identificación de nuestras contribuciones y el reconocimiento de una labor cotidiana de tanta importancia para nuestra sociedad.

El libro consta de ocho capítulos, una sección de introducción, referencias bibliográficas y tres apéndices. El primero y segundo capítulo refieren características y perspectivas teóricas de la investigación cualitativa, los siguientes seis siguen el ciclo del proceso de la investigación cualitativa desde la delimitación del problema o tema, siguiendo por la definición del diseño, las muestras, los métodos de producción de información, para concluir con la evaluación, reflexiones y sugerencias finales.

A continuación se expone una síntesis de los contenidos del libro por capítulos

El primer capítulo denominado caracterización de la investigación cualitativa, presenta un breve recorido histórico de la evolución de esta orientación en investigación, además describe las características generales que definen a la Investigación Cualitativa. Sus descripciones dibujan de modo sustantivo las particularidades que hacen de la investigación cualitativa un aporte distintivo en el concierto de la Investigación en Ciencias Sociales. Reconoce como diseños de carácter cualitativo el de estudio de casos, la etnografía, la historia oral, la investigación - acción participativa y la evaluación cualitativa.

Por otra parte, identifica las principales discusiones derivadas del carácter particular de la investigación cualitativa, el tema de la objetividad y sistematicidad de la investigación surge como uno de los puntos de discusión más recurrente.

El texto destaca la centralidad de la investigación social para el Trabajo Social, dada la complejidad de los problemas sociales y la exigencia ética de hacer uso del mejor conocimiento posible para dar cuent de la diversidad de estos problemas. Identifica igualmente, las características que facilitan al Trabajado 